\title{
SPECIFIC OF ACCOUNTING OF NON-FINANCIAL ASSETS IN HEALTH INSTITUTIONS
}

\author{
Natalya PRYADKA ${ }^{1}$ \\ Central Ukrainian National Technical University, Ukraine
}

\begin{abstract}
The purpose of the paper is to analysis of the modern state of accounting of non-financial assets and present accounting in health institutions protection during the period of medical reforms. The account of nonfinancial assets has his specific in medical establishments. Reforms, which implemented in Ukraine, affecting the account of non-financial assets. Medical institutions relate to the General government. Methodology. The survey is based on a comparison of data from the national and international reforms in medical industry. Results of the survey showed that in the dictionary of V. Raizberg next determination is driven: "public sector - it is a set of business units, that carry out economic activity, are in a public domain, controlled by public authorities or designated and hired persons" (Raizberg, 1999). In the Commercial code of Ukraine it is indicated: "The subjects of public sector of economy are subjects that operate on the basis of only public domain, and also subjects, which state share in authorized capital exceeds fifty percents or be value that provides a right to the state for decisive influence on economic activity of these subjects" (CC, 2003). Practical implications. Public sector structure specifies data of International Public Sector Accounting Standards. Substancial load concept "public sector" in national and international practice are relevant (Poznyakovska, 2009). Accounting in health institutions has specific terms, inherent to the government sector. They are determined by the types of activity and terms of assignation (Pasichnik, 2005). Medical services must be accessible to all stratum of population. They must have free basis. They come forward as a public benefit independent of individual possibility to pay for him. Therefore lion's part of general charges for health protection is used on the grant of medical services to the population. At the same time "upgrading of medical services lies inplane providing of unitization of going near the grant of medicare, standardization of medical documentation, approaching of services to the patients by their decentralization and integration, in accordance with health care level" (Eshchenko, 2016). Value/originality. Current state analysis of accounting non-financial assets of health care institutes has an important value. Account of non-financial assets influence on transference of data about non-financial assets to the financial reporting. A national account of nonfinancial assets is now reformating. This situation foresees changes and possible defects. The analysis of account gives an opportunity to avoid errors and defects.
\end{abstract}

Key words: non-financial assets, accounting, health care, public sector, public institutions.

JEL Classification: M41, I18, H42

\section{1. Вступиение}

Общественное развитие невозможно без существования и трансформации государственного сектора экономики. В словаре В. Райзберга приведено следующее определение: «государственный сектор - это совокупность хозяйствующих субъектов, которые осуществмяют экономическую Аеятельность, находятся в госуАарственной собственности, и управмяются госуАарственными органами или назначенными ними наемными лицами» (Raizberg, 1999). В то же время Хозяйственный кодекс Украины определяет, что: "Субъектами хозяйствования государственного сектора экономики явмяются субъекты, Аействующие на

\footnotetext{
Corresponding author:

${ }^{1}$ Central Ukrainian National Technical University.

E-mail:data0201@yandex.ru
}

основе государственной собственности, а также субъекты, государственная Аоля в уставном капитале которых превышает пятьдесят процентов или составмяет величину, которая обеспечивает госуАарству право решающего вмияния на хозяйственную Аеятельность этих субъектов "(Gospodars'kyj kodeks Ukrai'ny, 2003). Такое видение структуры государственного сектора конкретизирует опреАеление, которое дано в межАународных стандар-

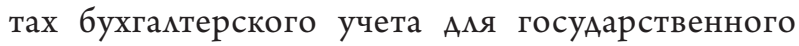
сектора, что подтвержАает соответствие смысмовой нагрузки понятия "государственный сектор" национацьной и международной практики (Poznyakovska, 2009). 


\section{2. Специфика нефинансовых активов меАицинских УчрежАений}

Свою специфику учета в государственном секторе имеют учрежАения зАравоохранения, ее опреАеляют виды деятельности и условия ассигнования (Pasichnyk, 2005). ВеАь меАицинские услуги Аолжны быть Аоступны всем слоям населения, то есть в своем составе иметь беспиатную основу, и выступать тем общественным благом независимым от индивиАуальной возможности заплатить за него. Поэтому Аьвиная Аоля общих расходов Аля зАравоохранения используется на предоставление медицинских услуг населению. В то же время "повышение качества меАицинских услуг межит в плоскости обеспечения унификации поАходов к оказанию меАицинской помощи, стандартизации меАицинской Аокументации, приближение ускуг к пациентам путем их Аецентрализации и интеграции, в соответствии с уровнями оказания медицинской помощи" (Eshchenko, 2016). Таким образом Аля обеспечения качества выполнения задач зАравоохранения необходимо современное обеспечение условиями труаа, а именно нефинансовыми активами, что предусматривает значительные объемы расходов на содержание отрасли. На фоне растущих потребностей общества в медицинском обеспечении обостряется необходимость исследования, анализа и обобщения фактической информации, которая производится и перегруппировывается в учетной системе.

Проблемы бюАжетного учета освещались в труAах известных отечественных и зарубежных ученых С.М. Алешин, И.А. Анареев, М.И. Баканов, Р.Т. Ажога, И.К. АрозА, А.М. Белов, Ф.Ф. Ефимова, П.Т. Ворончук, А.А. Грищенко, А.Н. ГомяАченко, Е.П. АеАков, О.В. Аышкант, П.С. Ещенко, Н.Н. Ермошкин, З.У. Жутова, А. Зверев, И.И. Каракоз, С.С. Котова, А. Киндрацкая, И.А. Кондратюк, Н.И. Малов, Ф.С. Михальчук, Ю. Пасечник, В.И. Самборский. За последние годы опубликованы результаты исследований П.И. Атамас, С.Я. Зубимевич, П. Петрашко, С.В. Свирко, Н.И. Сушко, А.А. Чечулина, И.А. Фарион. Анализ работ отечественных и зарубежных ученых подтверждает значимость и практическую ценность полученных научных результатов. Впрочем, пока не Аостаточно фундаментальных исследований в области учета и анализа Аеятельности медицинских учреждений, особенно в отношении учета нефинансовых активов. Аамьнейшего исслеАования требуют проблемы совершенствования методики их учета, анациза, концептуальных подходов к формированию и распреАелению в целях улучшения финансового состояния повышения эффективности использования и экономии ресурсов.

Целью исследования явмяется анализ современного состояния и перспектив реформирования бухгалтерского учета нефинансовых активов и их трансформация в отчетность учрежАений зАравоохранения на основе очерченных недостатков, пробцем и существующих базовых поАходов.

\section{3. Проблемы учетного процесса УчрежАений зАравоохранения}

Важным элементом современной инфраструктуры межАународной экономики выступает бухгалтерский учет и финансовая отчетность меАицинских учрежАений, в которых четко прослеживается анацитическая составцяющая. Поэтому в процессе совершенствования методики учета нефинансовых активов учрежАений зАравоохранения крайне необходимо обеспечить полноту формирования качественной информационной базы как основы принятия управленческих решений, направленных на повышение эффективности управления учрежАениями зАравоохранения, укучшения их экономики, обеспечения финансовой устойчивости, а значит, рентабельной Аеятемьности.

Труано не согласиться с мнением, что: "На законодательном уровне не существует разделения систем бухгалтерского учета, оАнако практика регулирования бухгалтерского учета в Украине свидетельствует, что такое распределение реально существует. Оно обусловлено формой собственности, масштабами и спецификой отАемьных видов Аеятемьности субъектов хозяйствования. Именно поэтому стандартизация бухгалтерского учета как на межАународном уровне, так и в Украине, происходит в рамках корпоративного, государственного секторов, малого и среднего бизнеса. СозАаваемые системы учета не являются автономными, все они базируются на еАиной методологии, но в организационном плане явцяются обособленными, поскольку имеют разное нормативное обеспечение, существенные особенности текущего учета, нюансы в смысле финансовой отчетности" (Kanjeva, 2010).

На базе учетных Аанных формируются пиановые мероприятия по финансированию отрасли, поэтому "обеспечения достаточного по объемам и эффективного финансирования является главным залогом нормального функционирования системы зАравоохранения в мюбой стране. Как свидетель-

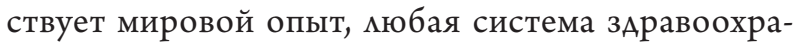
нения в большей или меньшей степени сталкивается с проблемой дефицита финансовых ресурсов. КажАая из стран Европейского Союза в свое время прибегала к реформированию национальной системы зАравоохранения. Каждая из стран шла своим собственным путем, но пробцемы, которые им приходилось решать, были оАинаковыми" (Malagardis, 2015). 


\section{4. Опыт проведения реформ стран Европы}

Следует заметить, что в странах Восточной Европы (Помьше, Эстонии, Хорватии, Венгрии, Словении), гАе Аостаточно низкий уровень неформальной экономики и занятости в том числе, новый поАХОА К финансированию зАравоохранения предусматривал не увеличение объема расходов, а имел целью их рациональное и оптимальное использование. В то же время страны с меньшей формальной занятостью (Россия, Румыния, Албания) не смогли ввести механизмы эффективного финансирования из-за особенностей выплат и налогообложения. Поэтому эффективное использование ресурсов выступает особенно важным моментом при реформировании отрасли. В Украине (государству с относительно высоким уровнем неформальной занятости) существует бюАжетная система финансирования и распределения ресурсов. В то же время, существует высокий процент неформальных платежей. Несмотря на то что зАравоохранение явмяется технически громозАкой отраслью, смеАующим шагом становится введение соответствующих специализированных компьютерных программ и оборудования. ВвоАится регистрация пациентов и медицинских услуг с использованием соответствующих компьютерных программ, ведется учет статистических данных на основе системы интегрированной отчетности (Malagardis, 2016).

Реализация положений пимотного проекта не обходится, конечно, без проблем. ОАной из них явмяется неготовность некоторых медицинских работников, особенно Аюдей старшего возраста, работать в новых условиях. ГАавная причина в этом заключается в отсутствии у них необходимых знаний и опыта, раскрыто в статье "Пикотные регионы работа проАолжается" (Malagardis, 2016).

"Необходимым фактором успешной автономизации мечебных учреждений явмяется коренное изменение организационной структуры управления предприятием. Важной составмяющей такой реорганизации является возможность руководителей разного уровня иметь оперативную и достоверную информацию о состоянии преАприятия и его поАраздемений по различным аспектам деятельности. В первую очередь это касается информации о состоянии финансового и материального обеспечения медицинского заведения, планирование бюджета и контроля за его выполнением, непрерывный анализ выполнения контрактных обязательств, расчета себестоимости оказанных медицинских ускуг, анализа качества этих ускуг и тому подобное. Успешное решение этих задач невозможно при традиционном бумажном накоплении информации и формировании отчетности. Итак остро стоит проблема замены бумажной технологии ведения документооборота на эмектронный с использованием компьютерного оборудования. Активное использова- ние аналитических и моделирующих возможностей информационных систем позволит руководителю оптимально смоделировать структуру своего кечебного учрежАения, правимьно организовать процесс пманирования бюджета и контроль за его выполнением. При этом экономия среАств может составить АО 20\%" (Djachenko, 2016).

B Украине продолжается выбор оптимального проекта реформирования зАравоохранения. Свои работы преАлагают не только Аеятели бюАжетной сферы, но и коммерческие идеологи, так В. КонАрук свое предложение обосновывает следующим образом: "В мире существует несколько успешных моделей предоставления медицинских услуг: частное финансирование зАравоохранения, которое пороАило самую успешную в мире меАицину - США (при этом, Аоступную не всем); модель Бисмарка (финансирование медицинских ускуг через обязательное страхование), которая успешно реализована в Германии; модель Бевериджа (бюджетное финансирование медицинских ускуг) - еще успешнее реализована в Великобритании. ОАнако, ответственная политика в мюбой сфере, особенно в такой чувствительной как зАравоохранение, Аолжна отталкиваться от реального положения Аел. Невозможно перенести модемь зАравоохранения, которая успешно работает в СоеАиненных Штатах Америки, Германии или Великобритании, на украинскую почву и сАекать эту модель такой же успешной в Украине. На сегодня полная разруха организации зАравоохранения в Украине Аает нашей стране уникальный шанс не копировать консервативную модель 200, 130 или 70-летней Аавности, которые успешно реализованы в США, Германии или в Англии, со всем известными преимуществами и недостатками той или иной модели, а создать новую модель, которая будет построена на современных достижениях и учтет положительный опыт организации зАравоохранения успешных стран и «Цели тысячелетия в области зАравоохранения» Всемирной организации зАравоохранения (ВО3). Поэтому Аля удобства в обсужАении этих преАложений я назвал новую модель организации здравоохранения - «Модель 5», подчеркивая этим, что она не повторяет ни одну из существующих четырех основных" (Kondruk, 2016).

\section{5. ПреАпосыкки реформирования сектора зАравоохранения}

Важно отметить, что стратегическое планирование Аеятельности медицинских учрежАений преАусматривает Алительный срок. Это определяется тем, что отрасль явмяется информационно и технологически насыщенной, базируется на Аорогом оборуАовании, документации, образах, результатах тестов и консультаций, и, немаловажно, существует уже действующий технологический процесс, и исполь- 
зование ресурсов Аолжно быть эффективным и качественным, что в свою очереАь обеспечивается современным техническим оснащением. Таким образом зАравоохранение явцяется капиталоемкой отраслью экономики, поэтому, очевидно, необходимо ожидать роста расходов в будущем. В то же время контроль качества - аудит, сертификация - приобретают все больший вес, когАа приходит время нехватки среАств.

По мнению польских ученых, а именно, Аж. Хиуска, учет в системе зАравоохранения Польши явцяется результатом выполнения условий политических, культурных, социальных, правовых, налоговых и финансовых требований, поэтому нестабильность в упомянутом секторе, проявцяется в постоянном изменении структуры зАравоохранения и отсутствии четкого регламента Аействий, конечно, это приводит к изменению правия финансирования ускуг меАицины. Что в свою очередь это провоцирует кратковременные подходы к реализации целей отрасли, в том числе и бухгалтерского учета (Chluska, 2004). А это в свою очередь не соответствует учетным принципам, таким как сопоставимости, непрерывности и Ар., ВеАь постоянные изменения в учетных методиках приводят к постоянной "подгонке" учетных Аанных к обновленным нормативным требованиям.

В свою очередь М. Macuda, в период формирования польской системы зАравоохранения, подчеркивац, что "внимание Аолжно быть уделено учету, как в целом, так и его подсистемам - финансовому и управленческому учету. Информация, полученная от управленческого учета, обеспечит отображение видов расходов в оценке меАицинского обслуживания. В то же время Аля внешних пользователей более интересна информация от финансового учета, то есть показатели финансового положения и нефинансовых активов учреждения в области здравоохранения, а также их миквидность", что бесспорно, также важно и Аля украинского учета (Macuda, 2013).

Методология, используемая в области польского бухгалтерского учета в системе зАравоохранения, является формой общественного Аоговора в рамках закона. Закон предусматривает, что влияние правильного применения стандартов будет:

1) определением Аостижений прошлого, что Аолжно обеспечить проверку изменения в методах управления и их влияние на эффективность функционирования;

2) получением информации Амя того, чтобы принимать рационамьные решения, касающиеся распределения ресурсов;

3) осуществлением управленческого планирования на основе статистической информации (Fijałkowska, 2014).

П. Атамас отмечает, что в бюАжетной сфере, почти отсутствуют хозрасчетные отношения, такие учрежАения не имеют уставного капитала, а все их активы явцяются госуАарственной собственностью (Atamas,
2003). Основным отличием бюджетных учреждений от Аругих неприбыльных организаций, как отмечает С. Аевицкая, явцяется их полная зависимость от бюАжетного финансирования, которое осуществцяется в рамках БюАжетного кодекса (Levyc'ka, 2004).

В то же время следует отметить, что в отличии от межАународной практики в системе бухгалтерского учета в бюАжетной сфере Украины размичают Ава основных объекта: учрежАение, получает среАства бюАжета, и собственно бюАжет. В отечественной практике учета исполнения бюАжетов применяется кассовый метоА отражения Аоходов и расходов. УчрежАения, которые получают средства бюАжетов, используют различные методы учета Аоходов и расходов. Так, учет Аоходов общего фонда сметы учрежАений осуществляется по кассовому методу (Kanjeva, 2010).

В сегодняшней жизни как украинского так и иностранного учета важный акцент получает учетная политика. Которая в себе Аолжна вместить и согласовать неоднозначности в трактовке законодательных актов по бухгалтерскому учету и меАицинских законов, а также их подзаконных нормативных документов, таким образом обеспечить сохранение учетных процессов, их соответствие принципам бухгалтерского учета. Как указывает Аж. Хћуска, в учетной политике Аолжны быть учтены процессы, как бюАжетного финансирования так и самофинансирования, и принимать во внимание не только положение баланса, но и Аругих действий, которые носят в себе характер организации функционирования субъекта Аеятельности. УАовлетворения информационных потребностей с учетом отАемьных партнеров, налоговиков, сотрудников, а также необходимость мониторинга и контромлинга конкретных задач может быть Аостигнуто за счет развития аналитики дополнительных счетов, которые подробно описывают синтетические счета общей бухгалтерской процеАуры (Chluska, 2012).

С точки зрения Аж. Хиуска бухгалтерский учет в медицинских учреждениях Аолжен охватывать всю информационную систему, которая играет важную роль в формировании финансовой отчетности, главная цель которой удовлетворить потребности внутренних и внешних пользователей, так учет в системе зАравоохранения явцяется результатом политической обстановки, культурных, социальных, правовых, налоговых и финансовых изменений в стране касательно государственного сектора экономики. Такие моменты созАают нестабильность Аанной отрасли, которая выражается в частых реструктуризациях, изменениях правил финансирования услуг медицинских учрежАений, структурных изменениях в системе зАравоохранения, несогласованности в остатках регионацьных политик, управлении колебаниями многих решений «по своему усмотрению», а это имеет принципиальное значение Амя 
функционирования больниц и вызывает отсутствие четкого регламента Аействий. Это в свою очереАь, становится причиной кратковременного подхода к реализации целей бухгалтерского учета. В результате кратковременного учета не всегда возможно выявить все проблемы и недочеты, с которыми сталкивается больница. Надежная и достоверная картина раскрывается в Аолгосрочной перспективе поэтому учетная политика Аолжна базироваться на индивидуальных подходах (с акцентом на принципы благоразумия) и быть ориентирована на генерацию информации, полезной в управлении меАицинским учреждением (Chluska, 2004).

\section{6. Закиючение}

В настоящее время в мировом сообществе наблюАается несколько моделей функционирования системы заравоохранения, которые в свою очередь имеют разАичные Подходы и методики к учету нефинансовых активов медицинских учреждений. Важен тот фактор, что каждая из них не идеальна и имеет свои недостатки.

Таким образом переА правительством Украины стоит важная задача поиска вариантов решений. Новые технологии способствуют более быстрому решению проблем зАравоохранения, но в то же время специфика отрасли заключается в уже существующем технологическом процессе и наличии влиятельных взглядов и мнений, которые не имеют жемания воспринимать обновленную систему. Важно заметить, что персонац государственных медицинских
УчрежАений Аостаточно консервативен. Нежелание стремительно воспринимать информационные потоки, приносит вреА в процессе экспериментальных пилотных проектов.

Итак, в Украине существует настоятельная необходимость разработки новой системы зАравоохранения, которая за основу взяла бы и накопленный опыт временами, и в то же время, не повторяла его ошибки. А это в свою очередь обеспечит бухгалтерский учет простой, прозрачной и Аостоверной информацией, которую мегко будет трактовать и использовать Аля внутренних и внешних потребностей.

ОАной из преграА выступает стремительное развитие технического обеспечения системы зАравоохранения, которое в свою очередь фактически относится к нефинансовым активам. Оборудование Аорогостоящее, поэтому не всегАа своевременно попадает в учреждения, а процесс ИТ - развития такой быстрый, что Ааже оборудование, на которое еще Аействительный полезный срок использования может быть морально устаревшим, и не отвечать требованиям общественного прогресса.

ВеАь бухгалтерский учет сталкивается с необходимостью согласовывать законы, регламентирующие учет и законы о медицинской деятельности, которые имеют влияние на принципы ведения бухгалтерского учета и накладывают на него существенный оттенок специфики отрасли. Поэтому бухгалтерский учет нефинансовых активов Аолжен проводиться так, чтобы не было никаких нарушений, которые возникают из-за комлизий в нормативно - законодательных актах.

\section{References}

Atamas P.J. (2003). Osnovy obliku v bjudzhetnyh organizacijah: navch. posib. - Harkiv: Centr navch. 1-ry, 284 s.

Chluska J. (2004) Rachunkowość zakładów opieki zdrowotnej w krótkim i długim czasie, w: Polska Szkoła Rachunkowości - Warszawie, SGH w Warszawie, 555 p.

Chluska J. (2012). Wartość godziwa w rachunkowości SPZOZ, w: Za i przeciw wartości godziwej w rachunkowości. Problemy stosowania i wykorzystania wartości godziwej - Katowicach, Wydawnictwo UE w Katowicach, 45 p.

Djachenko S. (2016). Rol' informacijnyh tehnologij v avtonomizacii' likars'kyh zakladiv, Elektronnyj resurs, Rezhym dostupu: http://www.healthfin.kiev.ua/pages/review/res_16u.htm

Fijałkowska B., J. Maroszek, red. J. Ostaszewski \& E. Kosycarz (2014). Kreowanie wyników finansowych samodzielnych publicznych zakładów opieki zdrowotnej za $2012 \mathrm{r}$. w: Rozwój nauki o finansach. Stan obecny i pożądane kierunki jej ewolucji - SGH w Warszawie, Oficyna Wydawnicza w Warszawa, 425 p.

Gospodars'kyj kodeks Ukrai'ny vid 16.01.2003 № 436-IV (2003). Vidomosti Verhovnoi' Rady Ukrai'ny (VVR), ((18)(19-20)(21-22)), 144 s., Elektronnyj resurs, rezhym dostupu: http://zakon5.rada.gov.ua/laws/ show $436-15$

Jeshhenko O. (2016). U Vinnyci tryvaje narada golovnyh likariv, Urjadovyj portal - Elektronnyj resurs, rezhym dostupu: http://www.kmu.gov.ua/control/publish/article?art_id=246456944

Kanjeva T., Shevchenko S. (2010). Stan i perspektyvy rozvytku obliku v derzhavnomu sektori Ukrai'ny - VISNYK KNTEUObliktaAudyt, (5/2010):33-40s. Elektronnyj resurs, Rezhym dostupu:5/2010http://www.nbuv.gov.ua/ old_jrn/soc_gum/vknteu/2010_5/4.pdf

Kondruk V.P. (2016). Z bjudzhetnym finansuvannjam medposlug zmyrylysja navit' u Velykij Brytanii' - Ukrinform, Elektronnyj resurs, rezhym dostupu: http://www.ukrinform.ua/rubric-society/2060715-valerij-kondruk-avtornovoi-modeli-ohoroni-zdorova-v-ukraini.html

Levyc'ka S.O. (2004). Oblik ta analiz dijal'nosti bjudzhetnyh ustanov: monografija - UDUVGP , Rivne, 233 s.

Macuda M., (2013). Rachunek wyników szpitala z wykorzystaniem jednorodnych grup pacjentów, rozprawa doktorska - UE w Poznaniu, Poznań, 63-72. 
Malagardis A. (2015). Strategichne planuvannja dlja efektyvnogo rozmishhennja resursiv ta upravlinnja medychnymy poslugamy v Ukrai'ni, Elektronnyj resurs, rezhym dostupu: http://www.healthfin.kiev.ua/pages/ review/res_19u.htm

Malagardis A. (2016). Pilotni regiony: robota prodovzhujet'sja, Urjadovyj portal - Elektronnyj resurs, rezhym dostupu: http://www.healthfin.kiev.ua/pages/review/res_10u.htm

PasichnykJu.V. (2005). Bjudzhetnyj potencial ekonomichnogo zrostannja v Ukrai'ni-Donec'k: TOV «JugoVostok, LTD $\gg$, monografija, $642 \mathrm{~s}$.

Poznjakovs'ka N.M. (2009). Problemy ta perspektyvy reformuvannja buhgalters'kogo obliku u derzhavnomu sektori - Visn. nac. un-tu vodnogo gosp-va ta pryrodokorystuvannja, (ch.2): 396-403.

Rajzberg B.A., L.Sh. Lozovskyj, E.B. Starodubceva (1999). Sovremennj ekonomycheskyj slovar' (2-e yzd., yspr.) YNFRA-M, Moskva, 477 s.

\section{Наталя ПРЯДКА \\ СПЕЦИФИКА И ПРОБЛЕМЫ УЧЕТА НЕФИНАНСОВЫХ АКТИВОВ СИСТЕМЫ ЗДРАВООХРАНЕНИЯ}

Аннотация. Целью данной работы является анализ современного состояния учета нефинансовых активов и отчетности в области здравоохранения в период медицинских реформ. Бухгалтерский учет нефинансовых активов имеет свою специфику в медицинских учреждениях. Реформы, которые проводятся в Украине имеют ключевое влияние на учет нефинансовых активов. Медицинские учреждения относятся к сектору государственного управления. Методология. Исследование основано на сопоставлении данных национальных и международных реформ в медицинской отрасли. Результаты исследования показали, что в словаре В. Райзберга приведено следующее определение: «государственный сектор - это совокупность хозяйствующих субъектов, осуществляющих экономическую деятельность, находятся в государственной собственности, управляются государственными органами или назначенными ними наемными лицами» (Rajzberg, 1999). В Хозяйственном кодексе Украины указано: "Субъектами хозяйствования государственного сектора экономики являются субъекты, действующие на основе государственной собственности, а также субъекты, государственная доля в уставном капитале которых превышает пятьдесят процентов или составляет величину, которая обеспечивает государству право решающего влияния на хозяйственную деятельность этих субъектов "(Gospodars'kyj kodeks Ukrai'ny, 2003). Практические достижения. Структура государственного сектора конкретизирует данные международных стандартов бухгалтерского учета для государственного сектора. Содержательные нагрузки понятия "государственный сектор" в национальной и международной практике соответствуют (Poznjakovs'ka, 2009). Учет в учреждениях здравоохранения имеет специфические условия, которые присущи всему государственному сектору. Но в то же время они определяются видами деятельности и условиями ассигнования. Медицинские услуги должны быть доступны всем слоям населения. Они должны иметь бесплатную основу. Они выступают общественным благом независимым от индивидуальной возможности заплатить за него. Поэтому львиная доля общих расходов для здравоохранения используется на предоставление медицинских услуг населению. В то же время "повышение качества медицинских услуг лежит в плоскости обеспечения унификации подходов к оказанию медицинской помощи, стандартизации медицинской документации, приближение услуг к пациентам путем их децентрализации и интеграции, в соответствии с уровнями оказания медицинской помощи" (Jeshhenko, 2016). Значение/оригинальность. Анализ современного состояния бухгалтерского учета нефинансовых активов учреждений здравоохранения имеет важное значение. Подходы к учетному процессу нефинансовых активов влияют на перенос данных о нефинансовых активах в финансовую отчетность. Национальный учет нефинансовых активов находится в процессе реформирования. Эта ситуация предполагает изменения и возможные недочеты. Анализ подходов к учету позволяет избежать ошибок и недостатков. 